\title{
Regulation of Macrophage and Dendritic Cell Function by Chondroitin Sulfate in Innate to Antigen-Specific Adaptive Immunity
}

\author{
Sonoko Hatano* and Hideto Watanabe \\ Institute for Molecular Science of Medicine, Aichi Medical University, Nagakute, Japan
}

Chondroitin sulfate (CS), a type of glycosaminoglycan (GAG), is a linear acidic polysaccharide comprised of repeating disaccharides, modified with sulfate groups at various positions. Except for hyaluronan (HA), GAGs are covalently bound to core proteins, forming proteoglycans (PGs). With highly negative charges, GAGs interact with a variety of physiologically active molecules, including cytokines, chemokines, and growth factors, and control cell behavior during development and in the progression of diseases, including cancer, infections, and inflammation. Heparan sulfate (HS), another type of GAG, and HA are well reported as regulators for leukocyte migration at sites of inflammation. There have been many reports on the regulation of immune cell function by $\mathrm{HS}$ and HA; however, regulation of immune cells by CS has not yet been fully understood. This article focuses on the regulatory function of CS in antigen-presenting cells, including macrophages and dendritic cells, and refers to CSPGs, such as versican and biglycan, and the cell surface proteoglycan, syndecan.

Keywords: chondroitin sulfate, glycosaminoglycan, proteoglycan, antigen-presenting cell, receptor type of protein tyrosine phosphatase sigma

\section{INTRODUCTION}

Glycosaminoglycans (GAGs) are linear polysaccharides consisting of repeating disaccharide units and modified with sulfate groups at various positions on the sugar residues. The GAG chains retain negatively charged domains due to characteristics of the sulfate groups, allowing for the absorption of water and other positively charged soluble ligands, such as chemokines $(1,2)$, cytokines (3), growth factors $(4,5)$, and cell surface receptors $(6,7)$. They are classified into chondroitin sulfate/dermatan sulfate (CS/DS), heparin/heparan sulfate (HP/HS), hyaluronan (HA), and keratan sulfate (KS).

At the site of injury or infection, macrophages release cytokines to activate endothelial cells, and HS on endothelial cells binds to L-selectins on leukocyte, leading to leukocyte rolling (8). Macrophages also release substantial amounts of chemokines that bind to GAGs at the endothelial surface (9). Leukocytes adhere to endothelial cells firmly and then migrate through the endothelial barrier. Therefore, the roles of GAGs in inflammation and immunity are linked to chemokines due to their highly polar nature. HA is best studied in clinical applications for its influence on inflammation, and its role is varying depending on its molecular weight. High-molecular-weight HA has anti-angiogenic, anti-inflammatory, and immunosuppressive effects (10). Conversely, low-molecular-weight HA promotes angiogenesis, inflammation, and cell migration (10, 11). HA 
forms provisional matrices with a CS proteoglycan (PG) versican. In the versican-null lung, there are no such matrices, and numbers of infiltrated leukocytes do not increase (12). The HA-versican interaction is important for the recruitment of inflammatory cells including neutrophils, macrophages, and $\mathrm{T}$ cells $(13,14)$. An early work showed a significant increase in CS synthesis in the normal lung after intravenous administration of a single dose of endotoxin (15).

Therefore, PGs accumulate in inflammatory areas and induce inflammatory cell infiltration. Increasing evidence suggests an anti-inflammatory activity of CS through suppression of proinflammatory cytokine activities (16-18). While the structurefunction relationship of CS is controversial, we aim to introduce the latest information on the role of CS in inflammation.

\section{STRUCTURE OF CHONDROITIN SULFATE}

Chondroitin sulfate (CS) is a natural biomacromolecule abundantly distributed in virtually all invertebrates and vertebrates and involved in many biological processes $(19,20)$. Based on its structure, chain length, and sulfation patterns, CS provides specific biological functions at molecular, cellular, and organ levels, such as cell adhesion, cell division and differentiation, morphogenesis, organogenesis, and neural network formation $(6,21)$. CS is composed of a repeating glucuronic acid (GlcA) and $N$-acetylgalactosamine (GalNAc) and modified with sulfate groups at varying positions on sugar residues. The major disaccharide structures of CS are as follows: a non-sulfated unit ( $\mathrm{CH}$, GlcA-GalNAc), a monosulfated unit at the $\mathrm{C}-4$ position of the GalNAc residue (chondroitin 4-sulfate: CSA, GlcA-GalNAc4S), a monosulfated unit at the C- 6 position of GalNAc (chondroitin 6-sulfate: CSC, GlcA-GalNAc6S), a disulfated unit at the C-4 and C-6 positions of GalNAc (chondroitin 4, 6-sulfate: CSE, GlcA-GalNAc4S6S), a disulfated unit at the C-2 position of GlcA and the C-4 position of GalNAc (chondroitin 2,4-sulfate, GlcA2S-GalNAc4S), a disulfated unit at the C-2 position of GlcA and the C- 6 position of GalNAc (chondroitin 2, 6-sulfate: CSD, GlcA2S-GalNAc6S), and a trisulfated unit at the C-2 position of GlcA and the C-4 and C-6 positions of GalNAc (GlcA2S-GalNAc4S6S). Certain GlcA residues are epimerized to iduronic acid (IdoA); the chain containing IdoA residues is designated as CSB or DS (Figure 1).

Thus, CS possesses a heterogeneous structure and physicalchemical profile in different species and tissues and is

\footnotetext{
Abbreviations: CS, chondroitin sulfate; GAG, glycosaminoglycan; HA, hyaluronan; PG, proteoglycan; CSPG, chondroitin sulfate proteoglycan; HS, heparan sulfate; DS, dermatan sulfate; HP, heparin; KS, keratan sulfate; GlcA, glucuronic acid; GalNAc, $N$-acetylgalactosamine; CSA, chondroitin 4-sulfate; CSC, chondroitin 6-sulfate; CSD, chondroitin 2,6-sulfate; CSE, chondroitin 4,6-sulfate; IdoA, iduronic acid; ECM, extracellular matrix; VAR2CSA, variant surface antigen 2-CSA; APC, antigen-presenting cell; DC, dendritic cell; PAMP, pathogen-associated molecular pattern; DAMP, damage-associated molecular pattern; PRR, pattern recognition receptor; TLR, Toll-like receptor; MHC, major histocompatibility complex; TNF- $\alpha$, tumor necrosis factor-alpha; IL, interleukin; LPS, lipopolysaccharide; IFN, interferon; EAE, experimental autoimmune encephalomyelitis; CNS, central nervous system; RPTP $\sigma$, receptor type of protein tyrosine phosphatase sigma; LAR, leukocyte common antigen-related; SLRP, small leucine-rich proteoglycan; LRR, leucine-rich repeat; LDL, low-density lipoprotein; SDC, syndecan.
}

responsible for the various and more specialized functions in the extracellular matrix (ECM). To understand the structurefunction relationship of CS, our group developed a sequence determination method of synthesized CS dodecasaccharides (22) and generated a CS library via chemo-enzymatic synthesis (23). This CS library showed that CSA interacts with a malarial variant surface antigen 2-CSA (VAR2CSA) protein and may potentially serve as a target in therapeutic strategies against placental malaria (24).

\section{THE EFFECT OF CHONDROITIN SULFATE ON ANTIGEN-PRESENTING CELLS (IDEM FOR MACROPHAGES AND DENDRITIC CELLS)}

Antigen-presenting cells (APCs), including macrophages, dendritic cells (DCs), and B cells, trigger innate immunity by different mechanisms (Figure 2). In the innate immune system, the recognition of extracellular pathogen is mainly mediated by macrophages and DCs in the mononuclear phagocyte system. They recognize pathogen-associated molecular patterns (PAMPs) brought by microbes and damage-associated molecular patterns (DAMPs) produced by damaged host cells through antigen-specific surface receptors, including pattern recognition receptors (PRRs) (25). Toll-like receptors (TLRs) represent a major PRR family. Once their extracellular domains bind PAMPs or DAMPs, the TLRs trigger an intracellular signaling pathway to activate various transcription factors such as nuclear factor $-\kappa \mathrm{B}(\mathrm{NF}-\kappa \mathrm{B})$. After recognizing their specific molecular patterns, APCs internalize antigens by phagocytosis, process them, and display the fragment of antigen on their surface with major histocompatibility complex (MHC) $(26,27)$. In general, macrophages remain at the inflammatory sites to eliminate pathogens and apoptotic cells by phagocytosis and clearance and produce pro-inflammatory cytokines. In contrast, DCs can travel to the draining lymph nodes and stimulate T cells $(28,29)$.

\section{The Role of Chondroitin Sulfate in Macrophages}

Macrophages are typically activated in a pro-inflammatory phenotype (M1) or an anti-inflammatory phenotype (M2). Furthermore, M2 macrophage is classified into four subdivisions, M2a, M2b, M2c, and M2d, depending on the applied stimuli and their protein expression profile (30). M1 secretes various pro-inflammatory cytokines and chemokines, such as tumor necrosis factor-alpha (TNF- $\alpha$ ), interleukin (IL)-1 $\beta$, IL-6, IL-8, etc., to scavenge pathogens (31), and M2 produces inflammation inhibitory factors, such as IL-10 and Arginase 1, to avoid excessive inflammation and promote tissue repair (32). Most tissue-resident macrophages are not originated from circulating hematopoietic stem cell-derived monocytes but developed from embryonic precursors including the yolk-sac macrophage or fetal liver monocytes $(33,34)$.

The anti-inflammatory activity of CS has been studied concerning macrophages. CS influences inflammatory processes by limiting NF- $\kappa \mathrm{B}$ signaling $(16,35)$ and also inhibits IL- $1 \beta$ induced liberation of pro-inflammatory genes, such as IL-6, 


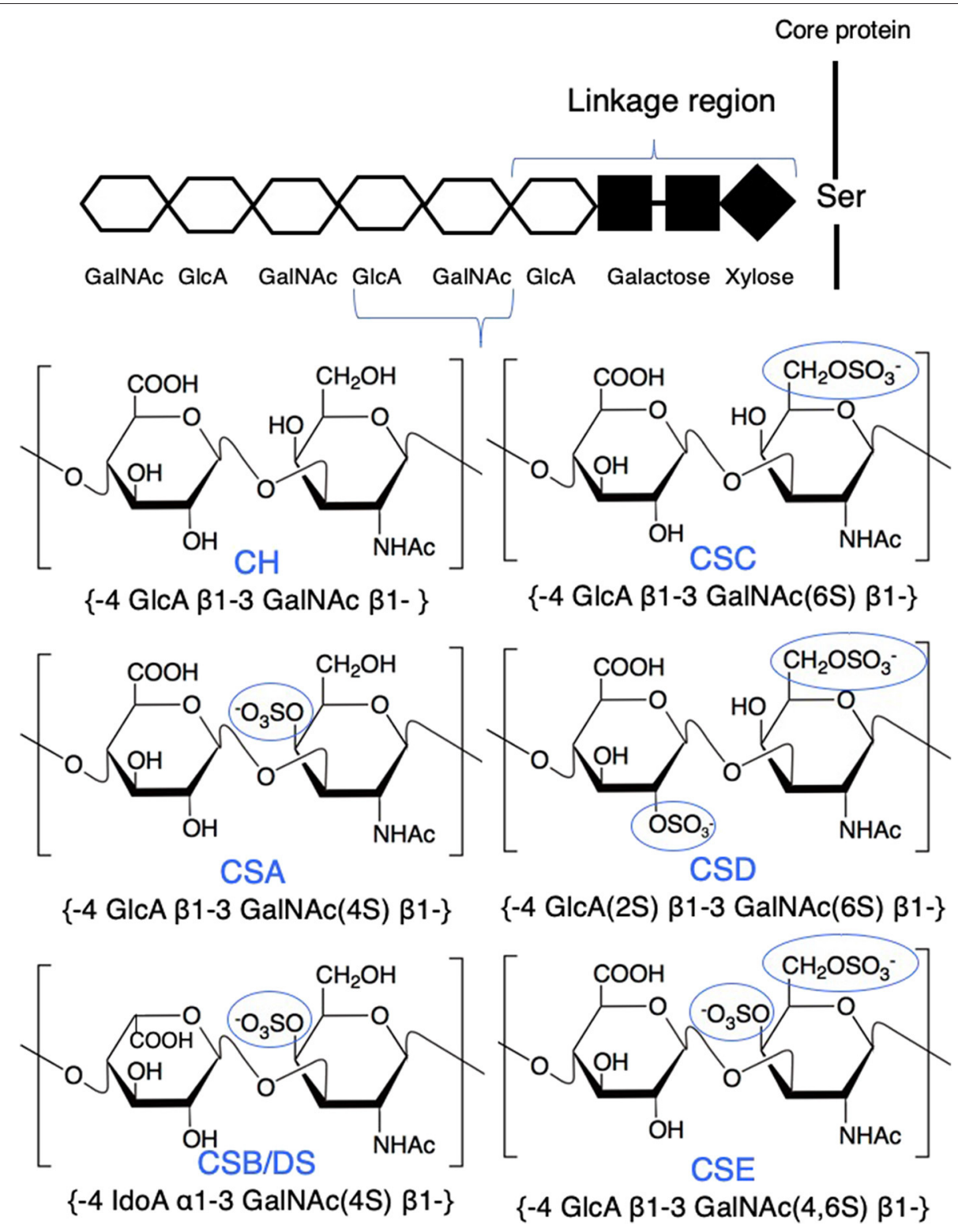

FIGURE 1 | Structure of major chondroitin sulfate (CS) disaccharides. CS is linked to a serine residue of a core protein via a linkage region. Repeating disaccharides form a linear polysaccharide chain, which is modified with sulfate groups at varying positions on sugar residues. The major disaccharide structures of CS are as follows: a non-sulfated unit (CH, GlcA-GalNAc); a monosulfated unit at the C-4 position of the GalNAc residue (CSA, GlcA-GalNAc4S); a monosulfated unit at the C-6 position of the GalNAc residue (CSC, GlcA-GalNAc6S); a disulfated unit at the C-2 position of GlcA and the C-6 position of the GalNAc residue (CSD,

GIcA2S-GalNAc6S); and a disulfated unit at the C-4 and the C-6 positions of the GalNAc residue (CSE, GlcA-GalNAc4S6S). Certain GlcA residues are epimerized to IdoA (CSB or DS, IdoA-GalNAc4S).

nitric oxide synthase 2, and prostaglandin E2 synthase (36, 37). Further, CS blocks lipopolysaccharide (LPS) binding to CD44 on rat bone marrow-derived macrophages to inhibit the LPS/CD44/NF-кB pathway (38). In CS structure, CSA and its $N$ deacetylated derivative can activate NF- $\mathrm{B}$ in macrophages and induce TNF- $\alpha$ production (39). In contrast, CSC attenuates the inflammatory response in macrophages via suppression of NF$\kappa \mathrm{B}$ nuclear translocation (40). Moreover, CSA or CSC inhibited the LPS-induced expression of TNF- $\alpha$, IL-1 $\beta$, IL-6, and nitric oxide (NO) on bone marrow-derived macrophages (36). The functions of the CS sulfated structures on macrophages are still in argument.

\section{The Role of Chondroitin Sulfate in Dendritic Cells}

Dendritic cells (DCs) are more potent APCs than macrophages and the major instructors of T cells (41). In local tissues, including 


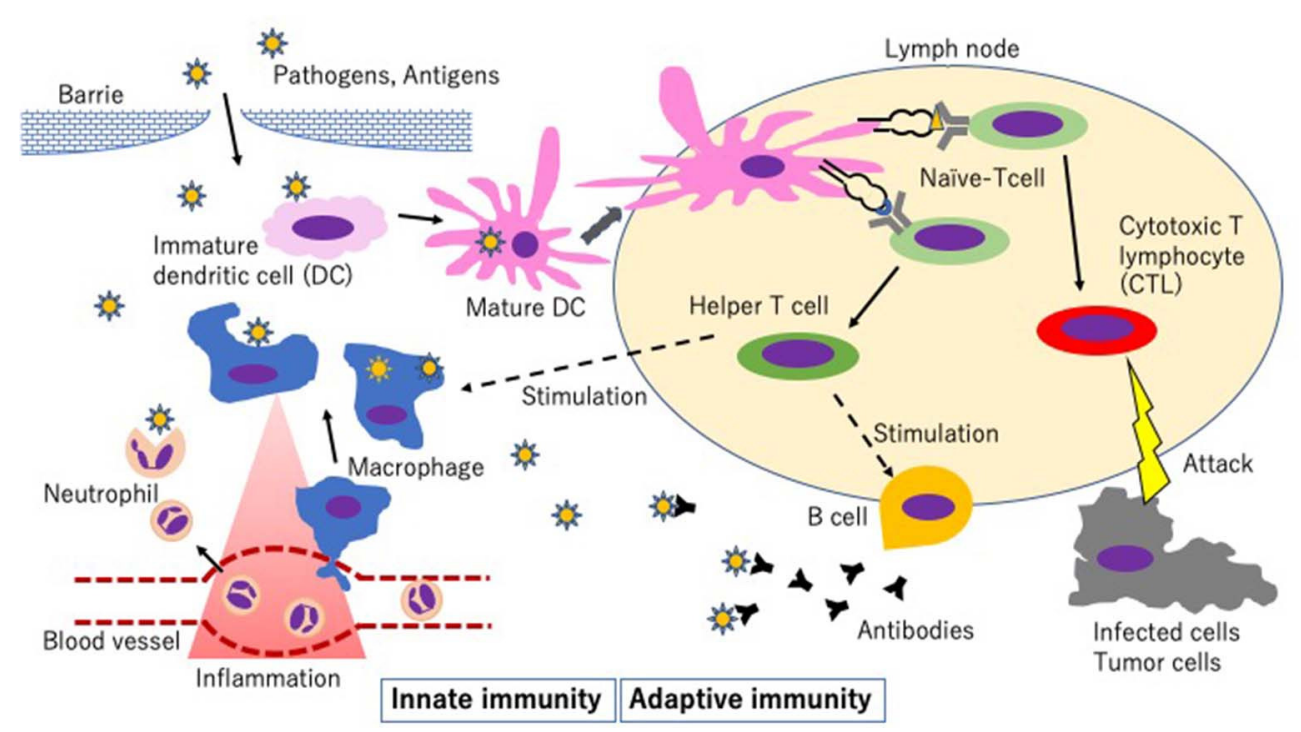

FIGURE 2 | Schematic diagram of innate immunity and adaptive immunity. Step 1: Activation of pattern recognition receptors (PRRs) on tissue-resident macrophages and/or dendritic cells (DCs) by pathogen-associated molecular patterns (PAMPs) resulting in activation of the innate immune response and the following events.

1. Migration of monocytes that mature into recruited macrophages and neutrophils in the systemic circulation.

2. Maturation of DCs, which then migrate to the lymph node.

Step 2: Processing of the antigens and presentation of an antigen on major histocompatibility complex I (MHC-I) or MHC-II to the T cell receptor on T cells.

Step 3: Development of adaptive immunity.

skin and intestine, DCs recognize PAMPs or DAMPs through a large variety of PRRs and phagocytose the antigens and become activated during this process. A variety of factors, such as IL-1 (42) and TNF- $\alpha$ (43), whole bacteria and microbial cell wall component LPS (44), CpG motifs in bacterial DNA (45), haptens (44), and apoptotic cells (44), stimulate DC maturation and promote the expression of $\mathrm{MHC}$-antigen-presenting and costimulatory molecules. The mature DCs migrate to nearby lymphoid organs to present the peptide to naive $\mathrm{T}$ cells in a complex with MHC proteins (28). Naive T cells can differentiate into several types of effector T cells via MHC class II complex and CD8 ${ }^{+}$T cells via MHC class I complex $(41,46-48)$. Effector cells include four types of helper $\mathrm{T}$ cells, namely, Th1, Th2, $\mathrm{T}_{\mathrm{FH}}$, Th17, and regulatory $\mathrm{T}$ cells, depending on the cytokines they encounter $(49,50)$. The mature DCs are divided into three major subsets of conventional DCs ( $\mathrm{cDC} 1 \mathrm{~s}$ and $\mathrm{cDC} 2 \mathrm{~s}$ ) and plasmacytoid DCs (pDCs). $\mathrm{cDC} 1$ has a high intrinsic capacity to cross-present antigens via MHC class I to activate $\mathrm{CD} 8^{+} \mathrm{T}$ cells and to promote Th1. $\mathrm{cDC} 2$ influences a wide range of naive $\mathrm{T}$ cell differentiation to Th1, Th2, Th17, and CD8 ${ }^{+} \mathrm{T}$ cells (51). Although pDCs are specialized to respond to viral infection with a massive production of type I interferons (IFNs), they also act as APCs and control T cell responses (28).

Both sulfate group content and position in CS are important for Th1 cell-promoted activity of murine splenocytes in terms of cytokine production (52). CSA exhibits the highest cytokine production activity in murine splenocytes. In contrast, CSE decreases Th1-promoted and Th2-inhibitory activity (53). A CSPG fraction mainly of aggrecan extracted from salmon nasal cartilage attenuates the severity of experimental autoimmune encephalomyelitis (EAE), by suppressing the differentiation of the Th17 lineage, and enhances regulatory $\mathrm{T}$ cell expansion (54). In EAE mice, treatment with CSD disaccharides inhibits the expression of IFN- $\gamma$ in the brain (55). CSD treatment also obviously alleviates the clinical symptoms of EAE by limiting $\mathrm{T}$ cell infiltration and microglial activation. However, CSA treatment exacerbates EAE symptoms by stimulating $\mathrm{T}$ cell infiltration in the central nervous system (CNS) and inducing their differentiation into Th1 and Th17 lineages (56). Moreover, CSC displayed a neuroprotective effect in EAE and may inhibit the spread of pathogenic T cells in the CNS (57). DCs play a pivotal role in promoting unbalanced active immune responses, resulting in the progression of autoimmune diseases. These results suggest that CS could regulate DC function, which leads to designated $\mathrm{T}$ cell differentiation.

\section{RECEPTORS OF CHONDROITIN SULFATE ON ANTIGEN-PRESENTING CELLS}

\section{Toll-Like Receptors}

The components of ECM are recognized by TLRs as DAMPs. To date, 13 mammalian TLRs have been identified. Each TLR recognizes specific PAMPs and DAMPs including lipopeptides for TLR1, TLR2, and TLR6, LPS for TLR4, bacterial flagellin for TLR5, dsRNA for TLR3, ssRNA for TLR7 and TLR8, and DNA for TLR9 (58). TLR2 and TLR4 can also be activated by endogenous ligands or DAMPs $(59,60)$. A small proteoglycan biglycan stimulates macrophage activation via TLR2 or TLR4. The effect is significantly reduced in 
TLR4-mutant and TLR2 ${ }^{-/}$macrophages and abolished in TLR2 ${ }^{-/-}$/TLR4-mutant macrophages (61). In cancer-associated inflammation, tumor-derived versican causes a dysfunction of DCs via activation of their TLR2 (62). Versican also facilitates Lewis lung carcinoma metastasis through TLR2 and its coreceptor TLR6 (63). Although versican and biglycan are CSPGs, these reports did not mention whether CS or core protein is responsible for these effects. In macrophage-like cell line, smaller sized CSA or its disaccharides suppress IL-6 secretion, whereas no such size-dependent suppression was apparent for CSC (21). CSA and CSC significantly inhibit NF- $\kappa \mathrm{B}$ activity and inflammatory cytokines via TLR4 (64). To elucidate the structure-function relationship between CSs and TLRs, further studies are expected.

\section{Receptor-Type Protein Tyrosine Phosphatase Sigma}

The receptor-type protein tyrosine phosphatase sigma (RPTP $\sigma)$ is found as an inhibitor of axonal growth and nerve regeneration with CS (65), and is a cell-surface protein that has intracellular tyrosine phosphatase activity and extracellular domains. RPTP $\sigma$ is one of the type IIa RPTPs, and others are leukocyte common antigen-related (LAR) and RPTP $\delta$. Out of the three, RPTP $\sigma$ is expressed in several immune cells, including DCs, and is essential for regulating immune cell activation, cytokine production, and inflammation $(66,67)$. RPTP $\sigma$ interacts with both CS and HP/HS in the nervous system, with a resembling binding affinity $(65,68$, 69). CS and HP/HS compete for the same binding site of RPTP $\sigma$ in the first Ig-like domain and result in opposing effects on axon elongation. Crystallographic analysis suggests that CS can prevent RPTP $\sigma$ dimerization, while HS induces RPTP $\sigma$ clustering (70). Using a biotin-conjugated CS GAG library composed of chemoenzymatically synthesized CS species, RPTP $\sigma$ binds to CSE with $10-\mathrm{kDa}$ molecular mass, but not to CSA or CSC (71).

$\mathrm{RPTP} \sigma$ acts as a receptor to inhibit autoimmune-related inflammation by preventing DC hyperactivation (66). Since RPTP $\sigma$ is crucial for suppressing immune responses mediated by DCs, the CS function through RPTP $\sigma$ might contribute to various immune-related diseases.

\section{CD44}

CD44 is a transmembrane glycoprotein that exhibits extensive molecular heterogeneity. The CD44 ectodomain is responsible for binding HA; low-molecular-weight HA triggers TLRmediated inflammation (72-74). In macrophages, biglycan and HA induce autophagy through interaction with $\operatorname{CD} 44(75,76)$. Besides biglycan and HA, versican (77), osteopontin $(78,79)$, and macrophage migration inhibitory factor (80) are also ligands of CD44. The cytoplasmic domain modulates inflammatory signaling in a ligand-dependent manner via TLR2 and TLR4 activity $(76,79,80)$.

CD44 is dramatically overexpressed on the surface of activated macrophages found at sites of inflammation, as such, it has been widely used as a receptor for targeted drug delivery (81-83). Given the relationship between CS and CD44, CS can be used to modify nanoparticles to enhance the cellular uptake of nanoparticles via CD44-mediated endocytosis $(84,85)$.
Remarkably, CS exhibits a high affinity for CD44 and facilitates cell internalization via CD44-mediated endocytosis $(86,87)$.

\section{THE ROLE OF CORE PROTEIN IN CHONDROITIN SULFATE PROTEOGLYCAN}

\section{Versican}

Versican is a large CSPG in the ECM and comprises a core protein of approximately $400 \mathrm{kDa}$, with approximately 20 attachment sites for CS side chains $(88,89)$. The core protein contains an N-terminal G1 domain and a C terminal G3 domain, with CS-attached domains between the two globular domains, and comprises four alternative splicing forms (V0, V1, V2, and V3). Versican interacts with HA at the G1 domain and other ECM molecules at the G3 domain. Versican acts on inflammatory responses as a DAMP via cell surface proteins such as CD44 (77, 90), CD162 (91), TLR2, TLR6, and CD14 (63, 92).

The versican gene is upregulated in monocytes/macrophages in some pro-inflammatory states, such as myocardial infarction (93), coronary stenosis (94), and autoimmunity (95-97). Experiments performed in vitro using classically activated murine bone marrow-derived macrophages treated with LPS showed that M1 type of macrophages exhibited a high expression level of versican mRNA, as well as versican accumulation (98). In human monocyte-to-macrophage differentiation and polarization, the versican gene expression level of M1 macrophages is higher than that of M2 macrophages (99). CSA and V1 core protein were upregulated in the perivascular cuff of multiple sclerosis and EAE and migration of leukocytes including macrophages across the glia limitans into the CNS parenchyma (100).

Versican secreted by Lewis lung carcinoma cells interacts with TLR2 on DCs and sensitizes DCs to respond with IL- 6 and IL-10 by increasing the expression of cell surface receptors for IL- 6 and IL-10 (62). This result indicates the protumor properties of intact versican. On the other hand, versikine, a degradation product of versican, also interacts with TLR2 on macrophages and acts with antitumor properties (101-103). Versikine is a $70-\mathrm{kDa} \mathrm{N}-$ terminal fragment (104), including the G1 domain and lacking CS-attached and the G3 domains. As the intact versican possesses a lot of functional domains including CS, there might be different manners to interact with TLR2.

We previously showed that embryonic fibroblasts, which express the mutant versican lacking the A-subdomain of the G1 domain, attain cell senescence (105). As there is a higher content of CSC and CSE in their conditioned media, the CS composition of the mutant versican could be altered (106). Changes in CS composition are probably caused by the changed core proteins.

\section{Biglycan}

The small leucine-rich proteoglycans (SLRPs) in the ECM regulate cell function in the inflammatory sites. Their core proteins have leucine-rich repeat (LRR) motifs and are attached with the CS and/or DS side chains. Biglycan is one of the SLRPs $(107,108)$ and consists of a $42-\mathrm{kDa}$ core protein containing 10 LRRs and up to two covalently bound CS and/or DS side chains. Biglycan interacts with types I, II, III, and VI collagen 
and regulates collagen fibrillogenesis (109-112). This regulation is mediated by the core protein, whereas the CS/DS side chains maintain interfibrillar space by extending outward from the protein core (113). The soluble form of biglycan initiates and perpetuates the inflammatory response by activating TLR2 and TLR4, and biglycan-deficient mice are less susceptible to death caused by TLR2- or TLR4-dependent sepsis (61). It is important that the biglycan core protein directly binds to CD44, and the GAG side chains enhance this interaction (75). Both the biglycan core protein and GAG side chain are also necessary for IL- $1 \beta$ maturation of macrophages (114). Sulfated CS/DS side chains are also implicated in lipid retention by direct interaction with low-density lipoprotein (LDL). In atherosclerotic plaque, LDL colocalizes with biglycan. The interaction between LDL and PGs promotes modification and aggregation of LDL, and uptake of LDL by macrophages leads to foam cell formation (115). Therefore, biglycan core protein plays a pivotal role in the suppression of inflammation and the transition from innate to adaptive immunity (116). Recently, an excellent review reported that biglycan, HA, and versican as the matrix-derived DAMPs regulate TLR-, CD14-, and CD44-signaling cross talk between inflammation and autophagy (85).

\section{Syndecan}

The syndecan (SDC) family of cell surface heparan sulfate proteoglycan mediates cell-cell and cell-matrix interactions via the GAG chains and is also important in the regulation of inflammation. SDCs are type I transmembrane proteoglycans and consist of four distinct members whose ectodomain varies among the members. SDC1 is widely expressed in epithelia and leukocytes. SDC2 is mainly expressed in endothelial cells and fibroblasts. SDC3 is expressed in neural tissues (117). SDC4 is abundant in many cell types and a soluble protein isoform lacking the transmembrane and cytoplasmic domains (118). Though HS is usually covalently attached to SDCs, SDC1 and SDC3 also bear two CS chains (119). Deletion of SDC1 leads to an exacerbation of allergic asthma (120). SDC4-deficient mice exhibit increased susceptibility to endotoxin shock (121). Although ubiquitous SDC4 expression is low in a steady state, SDC4 expression elevates in mice post-LPS stimulation of macrophages (122). Immature DCs express increased glypican1 and SDC1 compared to mature DCs, whereas mature DCs express glypican-3, which was not present in immature DCs (123). Research has illustrated that SDC1 on DC negatively regulates DC migration; therefore, lower SDC1 expression levels are often associated with mature DCs (124). Furthermore, the functional switch from SDC1 to SDC4 expression during DC

\section{REFERENCES}

1. Hirose J, Kawashima H, Yoshie O, Tashiro K, Miyasaka M. Versican interacts with chemokines and modulates cellular responses. J Biol Chem. (2001) 276:5228-34. doi: 10.1074/jbc.M007542200

2. Luster AD, Greenberg SM, Leder P. The IP-10 chemokine binds to a specific cell surface heparan sulfate site shared with platelet factor 4 and inhibits endothelial cell proliferation. J Exp Med. (1995) 182:219-31. doi: $10.1084 /$ jem.182.1.219 maturation controls DC motility and subsequent migration from peripheral sites to lymphoid tissues (125).

\section{CONCLUSION}

This mini-review described regulation of CS on APCs with their different structures through their specific receptors at inflammatory sites. CS exhibits both pro- and anti-inflammatory activities with their heterogeneous structures. Even with the same structure, CS affects differently depending on the target cells and their microenvironments. Regarding their sulfation patterns, CSC and CSD have anti-inflammatory activity, whereas CSA has both pro- and anti-inflammatory activities. In many cases, CSE has a potential anti-inflammatory activity, although a recent report suggests its stimulatory effect on tumor progression with the pro-inflammatory activity (6). Regarding the CS chain length, short chains such as oligosaccharides or disaccharides mostly activate inflammation, whereas the long chains serve as antiinflammatory factors. CS structure and length may vary by the different core proteins and their expressing cells. To understand detailed CS functions in immunity, further investigations into the structure-function relationship of CS are needed.

\section{AUTHOR CONTRIBUTIONS}

$\mathrm{SH}$ and HW contributed to the conception and design of the study. SH wrote the first draft of the manuscript and wrote sections of the manuscript. All authors contributed to manuscript revision, read and approved the submitted version.

SH took primary responsibility for communication with the journal and editorial office during the submission process, throughout peer review and during publication, ensuring that the submission adheres to all journal requirements including, but not exclusive to, details of authorship, study ethics and ethics approval, clinical trial registration documents and conflict of interest declaration, and available post-publication to respond to any queries or critiques.

\section{FUNDING}

This work was supported by JSPS KAKENHI (Grant No. 18H02646 to HW).

\section{ACKNOWLEDGMENTS}

We would like to thank Dr. Nobuo Sugiura and Dr. Tatsumasa Shioiri for their advice on CS structures.

3. Kuschert GS, Hoogewerf AJ, Proudfoot AE, Chung CW, Cooke RM, Hubbard RE, et al. Identification of a glycosaminoglycan binding surface on human interleukin-8. Biochemistry. (1998) 37:11193-201. doi: $10.1021 / \mathrm{bi9} 2867 \mathrm{o}$

4. Mizuguchi S, Uyama T, Kitagawa H, Nomura KH, Dejima K, GengyoAndo K, et al. Chondroitin proteoglycans are involved in cell division of Caenorhabditis elegans. Nature. (2003) 423:443-8. doi: 10.1038/nature01635

5. Kawakami Y, Kurihara Y, Saito Y, Fujita Y, Yamashita T, Takei K. The soluble form of LOTUS inhibits nogo receptor-mediated signaling 
by interfering with the interaction between nogo receptor type 1 and p75 neurotrophin receptor. J Neurosci. (2018) 38:2589-604. doi: 10.1523/JNEUROSCI.0953-17.2018

6. Kastana P, Choleva E, Poimenidi E, Karamanos N, Sugahara K, Papadimitriou E. Insight into the role of chondroitin sulfate $\mathrm{E}$ in angiogenesis. FEBS J. (2019) 286:2921-36. doi: 10.1111/febs. 14830

7. Zhang F, Zheng L, Cheng S, Peng Y, Fu L, Zhang X, et al. Comparison of the interactions of different growth factors and glycosaminoglycans. Molecules. (2019) 24:E3360. doi: 10.3390/molecules24183360

8. Parish CR. The role of heparan sulphate in inflammation. Nat Rev Immunol. (2006) 6:633-43. doi: 10.1038/nri1918

9. Webb LM, Ehrengruber MU, Clark-Lewis I, Baggiolini M, Rot A. Binding to heparan sulfate or heparin enhances neutrophil responses to interleukin 8. Proc Natl Acad Sci USA. (1993) 90:7158-62. doi: 10.1073/pnas.90.1 5.7158

10. Petrey AC, de la Motte CA. Hyaluronan, a crucial regulator of inflammation. Front Immunol. (2014) 5:101. doi: 10.3389/fimmu.2014.00101

11. Stern R, Asari AA, Sugahara KN. Hyaluronan fragments: an information-rich system. Eur J Cell Biol. (2006) 85:699-715. doi: 10.1016/j.ejcb.2006.05.009

12. Kang I, Harten IA, Chang MY, Braun KR, Sheih A, Nivison MP, et al. Versican deficiency significantly reduces lung inflammatory response induced by polyinosine-polycytidylic acid stimulation. J Biol Chem. (2017) 292:51-63. doi: 10.1074/jbc.M116.753186

13. Andersson-Sjoland A, Hallgren O, Rolandsson S, Weitoft M, Tykesson $\mathrm{E}$, Larsson-Callerfelt $\mathrm{AK}$, et al. Versican in inflammation and tissue remodeling: the impact on lung disorders. Glycobiology. (2015) 25:243-51. doi: $10.1093 /$ glycob/cwu120

14. Wight TN. Provisional matrix: a role for versican and hyaluronan. Matrix Biol. (2017) 60-61:38-56. doi: 10.1016/j.matbio.2016.12.001

15. Blackwood RA, Cantor JO, Moret J, Mandl I, Turino GM. Glycosaminoglycan synthesis in endotoxin-induced lung injury. Proc Soc Exp Biol Med. (1983) 174:343-9. doi: 10.3181/00379727-17441746

16. Xu CX, Jin H, Chung YS, Shin JY, Woo MA, Lee KH, et al. Chondroitin sulfate extracted from the styela clava tunic suppresses TNF-alpha-induced expression of inflammatory factors, VCAM-1 and iNOS by blocking Akt/NF-kappaB signal in JB6 cells. Cancer Lett. (2008) 264:93-100. doi: 10.1016/j.canlet.2008.01.022

17. Du Y, Carlson EC, Funderburgh ML, Birk DE, Pearlman E, Guo N, et al. Stem cell therapy restores transparency to defective murine corneas. Stem Cells. (2009) 27:1635-42. doi: 10.1002/stem.91

18. Stabler TV, Huang Z, Montell E, Verges J, Kraus VB. Chondroitin sulphate inhibits NF-kappaB activity induced by interaction of pathogenic and damage associated molecules. Osteoarthritis Cartilage. (2017) 25:166-74. doi: 10.1016/j.joca.2016.08.012

19. Volpi N. Anti-inflammatory activity of chondroitin sulphate: new functions from an old natural macromolecule. Inflammopharmacology. (2011) 19:299306. doi: 10.1007/s10787-011-0098-0

20. du Souich P, Garcia AG, Verges J, Montell E. Immunomodulatory and anti-inflammatory effects of chondroitin sulphate. J Cell Mol Med. (2009) 13:1451-63. doi: 10.1111/j.1582-4934.2009.00826.x

21. Jin M, Iwamoto T, Yamada K, Satsu H, Totsuka M, Shimizu M. Effects of chondroitin sulfate and its oligosaccharides on toll-like receptor-mediated IL-6 secretion by macrophage-like J774.1 cells. Biosci Biotechnol Biochem. (2011) 75:1283-9. doi: 10.1271/bbb.110055

22. Shioiri T, Tsuchimoto J, Watanabe H, Sugiura N. Sequence determination of synthesized chondroitin sulfate dodecasaccharides. Glycobiology. (2016) 26:592-606. doi: 10.1093/glycob/cww008

23. Sugiura N, Shioiri T, Chiba M, Sato T, Narimatsu H, Kimata K, et al. Construction of a chondroitin sulfate library with defined structures and analysis of molecular interactions. J Biol Chem. (2012) 287:43390-400. doi: $10.1074 /$ jbc.M112.412676

24. Sugiura N, Clausen TM, Shioiri T, Gustavsson T, Watanabe H, Salanti A. Molecular dissection of placental malaria protein VAR2CSA interaction with a chemo-enzymatically synthesized chondroitin sulfate library. Glycoconj J. (2016) 33:985-94. doi: 10.1007/s10719-016-9685-z
25. ten Broeke T, Wubbolts R, Stoorvogel W. MHC class II antigen presentation by dendritic cells regulated through endosomal sorting. Cold Spring Harb Perspect Biol. (2013) 5:a016873. doi: 10.1101/cshperspect.a016873

26. Steinman RM. The dendritic cell system and its role in immunogenicity. Аnnu Rev Immunol. (1991) 9:271-96. doi: 10.1146/annurev.iy.09.040191.001415

27. Gaudino SJ, Kumar P. Cross-talk between antigen presenting cells and $\mathrm{T}$ cells impacts intestinal homeostasis, bacterial infections, and tumorigenesis. Front Immunol. (2019) 10:360. doi: 10.3389/fimmu.2019. 00360

28. Geissmann F, Manz MG, Jung S, Sieweke MH, Merad M, Ley K. Development of monocytes, macrophages, and dendritic cells. Science. (2010) 327:656-61. doi: 10.1126/science.1178331

29. Grabowska J, Lopez-Venegas MA, Affandi AJ, den Haan JMM. CD169+ macrophages capture and dendritic cells instruct: the interplay of the gatekeeper and the general of the immune system. Front Immunol. (2018) 9:2472. doi: 10.3389/fimmu.2018.02472

30. Roszer T. Understanding the mysterious M2 macrophage through activation markers and effector mechanisms. Mediators Inflamm. (2015) 2015:816460. doi: $10.1155 / 2015 / 816460$

31. Liao WT, You HL, Li C, Chang JG, Chang SJ, Chen CJ. Cyclic GMPdependent protein kinase II is necessary for macrophage M1 polarization and phagocytosis via toll-like receptor 2. J Mol Med. (2015) 93:523-33. doi: 10.1007/s00109-014-1236-0

32. Zhang X, Xu F, Liu L, Feng L, Wu X, Shen Y, et al. (+)-Borneol improves the efficacy of edaravone against DSS-induced colitis by promoting M2 macrophages polarization via JAK2-STAT3 signaling pathway. Int Immunopharmacol. (2017) 53:1-10. doi: 10.1016/j.intimp.2017. 10.002

33. Guilliams M, van de Laar L. A hitchhiker's guide to myeloid cell subsets: practical implementation of a novel mononuclear phagocyte classification system. Front Immunol. (2015) 6:406. doi: 10.3389/fimmu.2015. 00406

34. Gordon S, Plüddemann A. The mononuclear phagocytic system. Generation of diversity. Front Immunol. (2019) 10:1893. doi: 10.3389/fimmu.2019. 01893

35. Jomphe C, Gabriac M, Hale TM, Heroux L, Trudeau LE, Deblois $\mathrm{D}$, et al. Chondroitin sulfate inhibits the nuclear translocation of nuclear factor-kappaB in interleukin-1beta-stimulated chondrocytes. Basic Clin Pharmacol Toxicol. (2008) 102:59-65. doi: 10.1111/j.1742-7843.2007. 00158.x

36. da Cunha AL, Aguiar JAK, Correa da Silva FS, Michelacci YM. Do chondroitin sulfates with different structures have different activities on chondrocytes and macrophages?. Int J Biol Macromol. (2017) 103:1019-31. doi: 10.1016/j.ijbiomac.2017.05.123

37. Gouze JN, Gouze E, Popp MP, Bush ML, Dacanay EA, Kay JD, et al. Exogenous glucosamine globally protects chondrocytes from the arthritogenic effects of IL-1beta. Arthritis Res Ther. (2006) 8:R173. doi: $10.1186 /$ ar2082

38. Taraballi F, Corradetti B, Minardi S, Powel S, Cabrera F, Van Eps $\mathrm{JL}$, et al. Biomimetic collagenous scaffold to tune inflammation by targeting macrophages. J Tissue Eng. (2016) 7:2041731415624667. doi: $10.1177 / 2041731415624667$

39. Zhang W, Sun F, Niu H, Wang Q, Duan J. Mechanistic insights into cellular immunity of chondroitin sulfate $\mathrm{A}$ and its zwitterionic N-deacetylated derivatives. Carbohydr Polym. (2015) 123:331-8. doi: 10.1016/j.carbpol.2015.01.059

40. Tan GK, Tabata Y. Chondroitin-6-sulfate attenuates inflammatory responses in murine macrophages via suppression of NF-kappaB nuclear translocation. Acta Biomater. (2014) 10:2684-92. doi: 10.1016/j.actbio.2014. 02.025

41. Kaufmann SHE. Immunology's coming of age. Front Immunol. (2019) 10:684. doi: 10.3389/fimmu.2019.01214

42. Yamada N, Katz SI. Generation of mature dendritic cells from a CD14+ cell line (XS52) by IL-4, TNF-alpha, IL-1 beta, and agonistic anti-CD40 monoclonal antibody. J Immunol. (1999) 163:5331-7.

43. Banchereau J, Steinman RM. Dendritic cells and the control of immunity. Nature. (1998) 392:245-52. doi: 10.1038/32588 
44. Rescigno M, Granucci F, Citterio S, Foti M, Ricciardi-Castagnoli P. Coordinated events during bacteria-induced DC maturation. Immunol Today. (1999) 20:200-3. doi: 10.1016/S0167-5699(98)01427-3

45. Jakob T, Walker PS, Krieg AM, Udey MC, Vogel JC. Activation of cutaneous dendritic cells by $\mathrm{CpG}$-containing oligodeoxynucleotides: a role for dendritic cells in the augmentation of Th1 responses by immunostimulatory DNA. $J$ Immunol. (1998) 161:3042-9.

46. Nierkens S, Tel J, Janssen E, Adema GJ. Antigen cross-presentation by dendritic cell subsets: one general or all sergeants? Trends Immunol. (2013) 34:361-70. doi: 10.1016/j.it.2013.02.007

47. Iwasaki A, Medzhitov R. Regulation of adaptive immunity by the innate immune system. Science. (2010) 327:291-5. doi: 10.1126/science.1 183021

48. Iwasaki A, Medzhitov R. Control of adaptive immunity by the innate immune system. Nat Immunol. (2015) 16:343-53. doi: 10.1038/ni.3123

49. Huang C, Yang X, Huang J, Liu X, Yang X, Jin H, et al. Porcine beta-defensin 2 provides protection against bacterial infection by a direct bactericidal activity and alleviates inflammation via interference with the TLR4/NFkappaB pathway. Front Immunol. (2019) 10:1673. doi: 10.3389/fimmu.2019. 01673

50. Zhu J, Paul WE. CD4 T cells: fates, functions, and faults. Blood. (2008) 112:1557-69. doi: 10.1182/blood-2008-05-078154

51. Collin M, Bigley V. Human dendritic cell subsets: an update. Immunology. (2018) 154:3-20. doi: 10.1111/imm.12888

52. Akiyama H, Sakai S, Linhardt RJ, Goda Y, Toida T, Maitani T. Chondroitin sulphate structure affects its immunological activities on murine splenocytes sensitized with ovalbumin. Biochem J. (2004) 382:26978. doi: $10.1042 / B J 20031851$

53. Toida T, Sakai S, Akiyama H, Linhardt RJ. Immunological activity of chondroitin sulfate. Adv Pharmacol. (2006) 53:403-15. doi: 10.1016/S1054-3589(05)53019-9

54. Sashinami H, Asano K, Yoshimura S, Mori F, Wakabayashi K, Nakane A. Salmon proteoglycan suppresses progression of mouse experimental autoimmune encephalomyelitis via regulation of Th17 and Foxp3(+) regulatory T cells. Life Sci. (2012) 91:1263-9. doi: 10.1016/j.lfs.2012.09.022

55. Rolls A, Cahalon L, Bakalash S, Avidan H, Lider O, Schwartz M. A sulfated disaccharide derived from chondroitin sulfate proteoglycan protects against inflammation-associated neurodegeneration. FASEB J. (2006) 20:547-9. doi: 10.1096/fj.05-4540fje

56. Zhou J, Nagarkatti P, Zhong Y, Nagarkatti M. Immune modulation by chondroitin sulfate and its degraded disaccharide product in the development of an experimental model of multiple sclerosis. $J$ Neuroimmunol. (2010) 223:55-64. doi: 10.1016/j.jneuroim.2010.04.002

57. Miyamoto $\mathrm{T}$, Inoue $\mathrm{H}$, Sakamoto $\mathrm{Y}$, Kudo E, Naito T, Mikawa T, et al. Identification of a novel splice site mutation of the CSPG2 gene in a Japanese family with wagner syndrome. Invest Ophthalmol Vis Sci. (2005) 46:2726-35. doi: 10.1167/iovs.05-0057

58. Sun L, Liu W, Zhang LJ. The role of toll-like receptors in skin host defense, psoriasis, and atopic dermatitis. J Immunol Res. (2019) 2019:1824624. doi: $10.1155 / 2019 / 1824624$

59. Gallo RL, Bernard JJ. Innate immune sensors stimulate inflammatory and immunosuppressive responses to UVB radiation. J Invest Dermatol. (2014) 134:1508-11. doi: 10.1038/jid.2014.32

60. Yu L, Wang L, Chen S. Endogenous toll-like receptor ligands and their biological significance. J Cell Mol Med. (2010) 14:2592-603. doi: 10.1111/j.1582-4934.2010.01127.x

61. Schaefer L, Babelova A, Kiss E, Hausser HJ, Baliova M, Krzyzankova M, et al. The matrix component biglycan is proinflammatory and signals through tolllike receptors 4 and 2 in macrophages. J Clin Invest. (2005) 115:2223-33. doi: $10.1172 /$ JCI23755

62. Tang M, Diao J, Gu H, Khatri I, Zhao J, Cattral MS. Toll-like receptor 2 activation promotes tumor dendritic cell dysfunction by regulating IL-6 and IL-10 receptor signaling. Cell Rep. (2015) 13:2851-64. doi: 10.1016/j.celrep.2015.11.053

63. Kim S, Takahashi H, Lin WW, Descargues P, Grivennikov S, Kim Y, et al. Carcinoma-produced factors activate myeloid cells through TLR2 to stimulate metastasis. Nature. (2009) 457:102-6. doi: 10.1038/nature07623
64. Campo GM, Avenoso A, Campo S, Traina P, D’Ascola A, Calatroni A. Glycosaminoglycans reduced inflammatory response by modulating toll-like receptor-4 in LPS-stimulated chondrocytes. Arch Biochem Biophys. (2009) 491:7-15. doi: 10.1016/j.abb.2009.09.017

65. Shen Y, Tenney AP, Busch SA, Horn KP, Cuascut FX, Liu K, et al. PTPsigma is a receptor for chondroitin sulfate proteoglycan, an inhibitor of neural regeneration. Science. (2009) 326:592-6. doi: 10.1126/science.1178310

66. Ohtake Y, Wong D, Abdul-Muneer PM, Selzer ME, Li S. Two PTP receptors mediate CSPG inhibition by convergent and divergent signaling pathways in neurons. Sci Rep. (2016) 6:37152. doi: 10.1038/srep37152

67. Ohtake Y, Saito A, Li S. Diverse functions of protein tyrosine phosphatase sigma in the nervous and immune systems. Exp Neurol. (2018) 302:196-204. doi: 10.1016/j.expneurol.2018.01.014

68. Fisher D, Xing B, Dill J, Li H, Hoang HH, Zhao Z, et al. Leukocyte common antigen-related phosphatase is a functional receptor for chondroitin sulfate proteoglycan axon growth inhibitors. J Neurosci. (2011) 31:14051-66. doi: 10.1523/JNEUROSCI.1737-11.2011

69. Dickendesher TL, Baldwin KT, Mironova YA, Koriyama Y, Raiker SJ, Askew $\mathrm{KL}$, et al. NgR1 and NgR3 are receptors for chondroitin sulfate proteoglycans. Nat Neurosci. (2012) 15:703-12. doi: 10.1038/nn.3070

70. Coles CH, Shen Y, Tenney AP, Siebold C, Sutton GC, Lu W, et al. Proteoglycan-specific molecular switch for RPTPsigma clustering and neuronal extension. Science. (2011) 332:484-8. doi: 10.1126/science.1200840

71. Tadai K, Shioiri T, Tsuchimoto J, Nagai N, Watanabe H, Sugiura $\mathrm{N}$. Interaction of receptor type of protein tyrosine phosphatase sigma (RPTPsigma) with a glycosaminoglycan library. J Biochem. (2018) 164:41-51. doi: $10.1093 / \mathrm{jb} / \mathrm{mvy} 027$

72. Ruppert SM, Hawn TR, Arrigoni A, Wight TN, Bollyky PL. Tissue integrity signals communicated by high-molecular weight hyaluronan and the resolution of inflammation. Immunol Res. (2014) 58:186-92. doi: 10.1007/s12026-014-8495-2

73. Powell JD, Horton MR. Threat matrix: low-molecular-weight hyaluronan (HA) as a danger signal. Immunol Res. (2005) 31:207-18. doi: 10.1385/IR:31:3:207

74. Hauser-Kawaguchi A, Luyt LG, Turley E. Design of peptide mimetics to block pro-inflammatory functions of HA fragments. Matrix Biol. (2019) 78-79:346-56. doi: 10.1016/j.matbio.2018.01.021

75. Poluzzi C, Nastase MV, Zeng-Brouwers J, Roedig H, Hsieh LT, Michaelis JB, et al. Biglycan evokes autophagy in macrophages via a novel CD44/Toll-like receptor 4 signaling axis in ischemia/reperfusion injury. Kidney Int. (2019) 95:540-62. doi: 10.1016/j.kint.2018.10.037

76. Taylor KR, Yamasaki K, Radek KA, Di Nardo A, Goodarzi H, Golenbock D, et al. Recognition of hyaluronan released in sterile injury involves a unique receptor complex dependent on toll-like receptor 4, CD44, and MD-2. J Biol Chem. (2007) 282:18265-75. doi: 10.1074/jbc.M606352200

77. Wu YJ, La Pierre DP, Wu J, Yee AJ, Yang BB. The interaction of versican with its binding partners. Cell Res. (2005) 15:483-94. doi: 10.1038/sj.cr.7290318

78. Kahles F, Findeisen HM, Bruemmer D. Osteopontin: a novel regulator at the cross roads of inflammation, obesity and diabetes. Mol Metab. (2014) 3:384-93. doi: 10.1016/j.molmet.2014.03.004

79. Castello LM, Raineri D, Salmi L, Clemente N, Vaschetto R, Quaglia M, et al. Osteopontin at the crossroads of inflammation and tumor progression. Mediators Inflamm. (2017) 2017:4049098. doi: 10.1155/2017/4049098

80. Shi X, Leng L, Wang T, Wang W, Du X, Li J, et al. CD44 is the signaling component of the macrophage migration inhibitory factor-CD74 receptor complex. Immunity. (2006) 25:595-606. doi: 10.1016/j.immuni.2006.08.020

81. Alam MM, Han HS, Sung S, Kang JH, Sa KH, Al Faruque H, et al. Endogenous inspired biomineral-installed hyaluronan nanoparticles as $\mathrm{pH}$ responsive carrier of methotrexate for rheumatoid arthritis. J Control Release. (2017) 252:62-72. doi: 10.1016/j.jconrel.2017.03.012

82. Xiao B, Zhang Z, Viennois E, Kang Y, Zhang M, Han MK, et al. Combination therapy for ulcerative colitis: orally targeted nanoparticles prevent mucosal damage and relieve inflammation. Theranostics. (2016) 6:2250-66. doi: 10.7150/thno.15710

83. Rios de la Rosa JM, Tirella A, Gennari A, Stratford IJ, Tirelli N. The CD44Mediated uptake of hyaluronic acid-based carriers in macrophages. $A d v$ Healthc Mater. (2017) 6:201601012. doi: 10.1002/adhm.201601012 
84. Lee JY, Chung SJ, Cho HJ, Kim DD. Bile acid-conjugated chondroitin sulfate a-based nanoparticles for tumor-targeted anticancer drug delivery. Eur J Pharm Biopharm. (2015) 94:532-41. doi: 10.1016/j.ejpb.2015.06.011

85. Roedig H, Damiescu R, Zeng-Brouwers J, Kutija I, Trebicka J, Wygrecka M, et al. Danger matrix molecules orchestrate CD14/CD44 signaling in cancer development. Semin Cancer Biol. (2019). doi: 10.1016/j.semcancer.2019.07.026. [Epub ahead of print].

86. Zhou B, Weigel JA, Fauss L, Weigel PH. Identification of the hyaluronan receptor for endocytosis (HARE). J Biol Chem. (2000) 275:37733-41. doi: 10.1074/jbc.M003030200

87. Tsai HY, Chiu CC, Lin PC, Chen SH, Huang SJ, Wang LF. Antitumor efficacy of doxorubicin released from crosslinked nanoparticulate chondroitin sulfate/chitosan polyelectrolyte complexes. Macromol Biosci. (2011) 11:6808. doi: 10.1002/mabi.201000456

88. Zimmermann DR, Ruoslahti E. Multiple domains of the large fibroblast proteoglycan, versican. Embo J. (1989) 8:2975-81. doi: 10.1002/j.1460-2075.1989.tb08447.x

89. Shinomura T, Nishida Y, Ito K, Kimata K, Kern, Kern CB. CDNA cloning of PG-M, a large chondroitin sulfate proteoglycan expressed during chondrogenesis in chick limb buds. Alternative spliced multiforms of PG-M and their relationships to versican. J Biol Chem. (1993) 268:14461-9.

90. Kawashima H, Hirose M, Hirose J, Nagakubo D, Plaas AH, Miyasaka M. Binding of a large chondroitin sulfate/dermatan sulfate proteoglycan, versican, to L-selectin, P-selectin, and CD44. J Biol Chem. (2000) 275:3544856. doi: 10.1074/jbc.M003387200

91. Zheng PS, Wen J, Ang LC, Sheng W, Viloria-Petit A, Wang Y, et al. Versican/PG-M G3 domain promotes tumor growth and angiogenesis. Faseb J. (2004) 18:754-6. doi: 10.1096/fj.03-0545fje

92. Wang W, Xu GL, Jia WD, Ma JL, Li JS, Ge YS, et al. Ligation of TLR2 by versican: a link between inflammation and metastasis. Arch Med Res. (2009) 40:321-3. doi: 10.1016/j.arcmed.2009.04.005

93. Toeda K, Nakamura K, Hirohata S, Hatipoglu OF, Demircan K, Yamawaki $\mathrm{H}$, et al. Versican is induced in infiltrating monocytes in myocardial infarction. Mol Cell Biochem. (2005) 280:47-56. doi: 10.1007/s11010-0058051-4

94. Wingrove JA, Daniels SE, Sehnert AJ, Tingley W, Elashoff MR, Rosenberg $S$, et al. Correlation of peripheral-blood gene expression with the extent of coronary artery stenosis. Circ Cardiovasc Genet. (2008) 1:31-8. doi: 10.1161/CIRCGENETICS.108.782730

95. Olsen NJ, Moore JH, Aune TM. Gene expression signatures for autoimmune disease in peripheral blood mononuclear cells. Arthritis Res Ther. (2004) 6:120-8. doi: 10.1186/ar1190

96. Shou J, Bull CM, Li L, Qian HR, Wei T, Luo S, et al. Identification of blood biomarkers of rheumatoid arthritis by transcript profiling of peripheral blood mononuclear cells from the rat collagen-induced arthritis model. Arthritis Res Ther. (2006) 8:R28. doi: 10.1186/ar1883

97. Masuda A, Yasuoka H, Satoh T, Okazaki Y, Yamaguchi Y, Kuwana M. Versican is upregulated in circulating monocytes in patients with systemic sclerosis and amplifies a CCL2-mediated pathogenic loop. Arthritis Res Ther. (2013) 15:R74. doi: 10.1186/ar4251

98. Chang MY, Tanino Y, Vidova V, Kinsella MG, Chan CK, Johnson PY, et al. A rapid increase in macrophage-derived versican and hyaluronan in infectious lung disease. Matrix Biol. (2014) 34:1-12. doi: 10.1016/j.matbio.2014.01.011

99. Martinez FO, Gordon S, Locati M, Mantovani A. Transcriptional profiling of the human monocyte-to-macrophage differentiation and polarization: new molecules and patterns of gene expression. J Immunol. (2006) 177:7303-11. doi: 10.4049/jimmunol.177.10.7303

100. Stephenson EL, Mishra MK, Moussienko D, Laflamme N, Rivest S, Ling CC, et al. Chondroitin sulfate proteoglycans as novel drivers of leucocyte infiltration in multiple sclerosis. Brain. (2018) 141:1094-110. doi: 10.1093/brain/awy033

101. Hope C, Foulcer S, Jagodinsky J, Chen SX, Jensen JL, Patel S, et al. Immunoregulatory roles of versican proteolysis in the myeloma microenvironment. Blood. (2016) 128:680-5. doi: 10.1182/blood-2016-03-7 05780

102. Hope C, Emmerich PB, Papadas A, Pagenkopf A, Matkowskyj KA, Van De Hey DR, et al. Versican-derived matrikines regulate batf3-dendritic cell differentiation and promote $\mathrm{T}$ cell infiltration in colorectal cancer. $J$ Immunol. (2017) 199:1933-41. doi: 10.4049/jimmunol.1700529

103. Binder MJ, McCoombe S, Williams ED, McCulloch DR, Ward AC. The extracellular matrix in cancer progression: role of hyalectan proteoglycans and ADAMTS enzymes. Cancer Lett. (2017) 385:55-64. doi: 10.1016/j.canlet.2016.11.001

104. Sandy JD, Westling J, Kenagy RD, Iruela-Arispe ML, Verscharen C, Rodriguez-Mazaneque JC, et al. Versican V1 proteolysis in human aorta in vivo occurs at the Glu441-Ala442 bond, a site that is cleaved by recombinant ADAMTS-1 and ADAMTS-4. J Biol Chem. (2001) 276:13372-8. doi: 10.1074/jbc.M009737200

105. Suwan K, Choocheep K, Hatano S, Kongtawelert P, Kimata K, Watanabe H. Versican/PG-M assembles hyaluronan into extracellular matrix and inhibits CD44-mediated signaling toward premature senescence in embryonic fibroblasts. J Biol Chem. (2009) 284:8596-604. doi: 10.1074/jbc.M806 927200

106. Suwan K, Hatano S, Kongtawelert P, Pothacharoen P, Watanabe H. Alteration of chondroitin sulfate composition on proteoglycan produced by knock-in mouse embryonic fibroblasts whose versican lacks the A subdomain. Ups J Med Sci. (2009) 114:73-81. doi: 10.1080/03009730902761722

107. Nastase MV, Young MF, Schaefer L. Biglycan: a multivalent proteoglycan providing structure and signals. J Histochem Cytochem. (2012) 60:963-75. doi: $10.1369 / 0022155412456380$

108. Schaefer L, Schaefer RM. Proteoglycans: from structural compounds to signaling molecules. Cell Tissue Res. (2010) 339:237-46. doi: 10.1007/s00441-009-0821-y

109. Wiberg C, Hedbom E, Khairullina A, Lamande SR, Oldberg A, Timpl R, et al. Biglycan and decorin bind close to the n-terminal region of the collagen VI triple helix. J Biol Chem. (2001) 276:18947-52. doi: 10.1074/jbc.M1006 25200

110. Wiberg C, Heinegard D, Wenglen C, Timpl R, Morgelin M. Biglycan organizes collagen VI into hexagonal-like networks resembling tissue structures. J Biol Chem. (2002) 277:49120-6. doi: 10.1074/jbc.M2068 91200

111. Wiberg C, Klatt AR, Wagener R, Paulsson M, Bateman JF, Heinegard D, et al. Complexes of matrilin-1 and biglycan or decorin connect collagen VI microfibrils to both collagen II and aggrecan. J Biol Chem. (2003) 278:37698704. doi: 10.1074/jbc.M304638200

112. Douglas T, Heinemann S, Bierbaum S, Scharnweber D, Worch H. Fibrillogenesis of collagen types I, II, and III with small leucine-rich proteoglycans decorin and biglycan. Biomacromolecules. (2006) 7:2388-93. doi: 10.1021/bm0603746

113. Iozzo RV. The biology of the small leucine-rich proteoglycans. Functional network of interactive proteins. J Biol Chem. (1999) 274:18843-6. doi: 10.1074/jbc.274.27.18843

114. Babelova A, Moreth K, Tsalastra-Greul W, Zeng-Brouwers J, Eickelberg O, Young MF, et al. Biglycan, a danger signal that activates the NLRP3 inflammasome via toll-like and P2X receptors. J Biol Chem. (2009) 284:24035-48. doi: 10.1074/jbc.M109.014266

115. Hultgardh-Nilsson A, Boren J, Chakravarti S. The small leucine-rich repeat proteoglycans in tissue repair and atherosclerosis. J Intern Med. (2015) 278:447-61. doi: 10.1111/joim.12400

116. Zeng-Brouwers J, Beckmann J, Nastase MV, Iozzo RV, Schaefer L. De novo expression of circulating biglycan evokes an innate inflammatory tissue response via MyD88/TRIF pathways. Matrix Biol. (2014) 35:132-42. doi: 10.1016/j.matbio.2013.12.003

117. Gondelaud F, Ricard-Blum S. Structures and interactions of syndecans. FEBS J. (2019) 286:2994-3007. doi: 10.1111/febs.14828

118. Xing $\mathrm{Y}, \mathrm{Xu} \mathrm{Q}$, Lee C. Widespread production of novel soluble protein isoforms by alternative splicing removal of transmembrane anchoring domains. FEBS Lett. (2003) 555:572-8. doi: 10.1016/S0014-5793(03) 01354-1

119. Couchman JR. Transmembrane signaling proteoglycans. Annu Rev Cell Dev Biol. (2010) 26:89-114. doi: 10.1146/annurev-cellbio-100109-104126

120. Xu J, Park PW, Kheradmand F, Corry DB. Endogenous attenuation of allergic lung inflammation by syndecan-1. J Immunol. (2005) 174:5758-65. doi: 10.4049/jimmunol.174.9.5758 
121. Ishiguro K, Kojima $\mathrm{T}$, Muramatsu $\mathrm{T}$. Syndecan-4 as a molecule involved in defense mechanisms. Glycoconj J. (2002) 19:315-8. doi: 10.1023/A:1025308702966

122. Ishiguro $K$, Kadomatsu $K$, Kojima $T$, Muramatsu $H$, Iwase $M$, Yoshikai Y, et al. Syndecan-4 deficiency leads to high mortality of lipopolysaccharide-injected mice. J Biol Chem. (2001) 276:47483-8. doi: 10.1074/jbc.M106268200

123. Wegrowski Y, Milard AL, Kotlarz G, Toulmonde E, Maquart FX, Bernard J. Cell surface proteoglycan expression during maturation of human monocytes-derived dendritic cells and macrophages. Clin Exp Immunol. (2006) 144:485-93. doi: 10.1111/j.1365-2249.2006. 03059.x

124. Averbeck M, Kuhn S, Buhligen J, Gotte M, Simon JC, Polte T. Syndecan-1 regulates dendritic cell migration in cutaneous hypersensitivity to haptens. Exp Dermatol. (2017) 26:1060-7. doi: 10.1111/exd.13374
125. Averbeck M, Gebhardt C, Anderegg U, Termeer C, Sleeman JP, Simon JC Switch in syndecan-1 and syndecan-4 expression controls maturation associated dendritic cell motility. Exp Dermatol. (2007) 16:580-9. doi: 10.1111/j.1600-0625.2007.00568.x

Conflict of Interest: The authors declare that the research was conducted in the absence of any commercial or financial relationships that could be construed as a potential conflict of interest.

Copyright (c) 2020 Hatano and Watanabe. This is an open-access article distributed under the terms of the Creative Commons Attribution License (CC BY). The use, distribution or reproduction in other forums is permitted, provided the original author(s) and the copyright owner(s) are credited and that the original publication in this journal is cited, in accordance with accepted academic practice. No use, distribution or reproduction is permitted which does not comply with these terms. 